\title{
NOVOS NEXOS ENTRE OS CIRCUITOS DA ECONOMIA URBANA NAS METRÓPOLES BRASILEIRAS
}

\author{
new links between the circuits of the urban economy \\ in the brazilian metropolises
}

\author{
Marina Regitz Montenegro ${ }^{1}$
}

$a a_{a a}$

\begin{abstract}
Resumo
No período atual, a divisão territorial do trabalho hegemônica se pauta sobre conteúdos intensivos em técnica, informação e finanças, ou seja, sobre as variáveis determinantes da globalização. Essas mesmas variáveis têm se tornado, contudo, progressivamente dominantes, na medida em que atingem e remodelam as demais divisões territoriais do trabalho: os circuitos inferior e superior marginal. Enquanto divisões do trabalho concorrentes e complementares, as atividades urbanas, exercidas por grupos com variados graus de tecnologia, capital e organização, podem ser vistas como um "circuito superior", com sua respectiva porção marginal, e um "circuito inferior". Quando estes conteúdos são altos, trata-se do circuito superior; quando são baixos, trata-se do circuito inferior. Nos dias de hoje, há uma expansão substancial do circuito inferior nas maiores cidades brasileiras. No entanto, para além desta expansão quantitativa, verifica-se também uma intensa renovação de suas dinâmicas e de suas relações com o circuito superior, haja vista a crescente difusão e assimilação das possibilidades da época atual entre os atores não hegemônicos.
\end{abstract}

Palavras-chave: Circuito inferior, Globalização, Metrópole, Consumo, Finanças.

\begin{abstract}
In the current period, the hegemonic territorial division of labor sustains itself in intensive contents of technique, information and finance, in other words, on the determinant variables of globalization. These same variables have become, however, progressively dominants, in so far as they affect and remodel the other divisions of labor: the lower and the marginal upper circuits. As concurrent and complementary divisions of labor, the urban activities, carried out by groups with varying degrees of technology, capital and organization, can be analyzed as an "upper circuit", with its marginal portion, and a "lower circuit". When these contents are high, it is the upper circuit; when they are low, it is the lower circuit. Nowadays, there is an expressive expansion of the lower circuit in the largest Brazilian cities. However, in addition to this quantitative expansion, there is also an intense renewal of its dynamics and its relations with the upper circuit, considering the increasing diffusion and assimilation of the possibilities of the recent period between non hegemonic actors.
\end{abstract}

Key words: Lower circuit, Globalization, Metropolis, Consumption, Finances.

\section{Résumé}

Dans la période actuelle, la division territoriale du travail hégémonique est soutenue par des contenus intensifs de technique, d'information et des finances, c'est-à-dire, par les variables déterminantes de la globalisation. Ces mêmes variables sont devenues, cependant, progressivement dominantes, dans la mesure où elles affectent et remodèlent les autres divisions de travail : les circuits inférieur et supérieur marginaux. En tant que divisions de travail concurrentes et complémentaires, les activités urbaines, effectuées par des groupes avec des divers niveaux de technologie, capital et organisation, peuvent être comprises comme un «circuit supérieur», avec sa portion marginale, et un " circuit inférieur ». Quand ces contenus sont élevés, il s'agit du circuit supérieur; quand ils sont bas, il s'agit du circuit inférieur. Il y a actuellement une expansion substantielle du circuit inférieur dans les plus grandes villes brésiliennes. Cependant, en plus de cette expansion quantitative, il y a également un intense renouvellement de ses dynamiques et de ses relations avec le circuit supérieur, compte tenu de la diffusion et de l'assimilation croissantes des possibilités de la période actuelle entre les acteurs non hégémoniques.

Mots-clé : Circuit inférieur, Globalisation, Métropole, Consommation, Finances.

(1) Doutora Pelo Programa de Pós-Graduação em Geografia Humana da Universidade de São Paulo - Av. Prof. Lineu Prestes, 338. CEP: 05508-000 - Sao Paulo (SP), Brasil. Tel (+55 11) 30913775 - montenegromarina@hotmail.com

\section{aaAaa}




\section{INTRODUÇÃO}

O processo de urbanização intensificou-se nos países subdesenvolvidos a partir de meados do século XX. A concentração da população nas cidades foi acompanhada, contudo, por limitações na capacidade empregatícia dos setores intensivos em capital e pela proliferação da pobreza e de atividades urbanas de baixa produtividade que acolhiam grande parte da força de trabalho. Neste momento, o processo de urbanização combinava-se, assim, com uma verdadeira "crise do emprego". Frente a este cenário, emergiu certa inquietação no debate internacional com a incapacidade de geração de oportunidades salariais e com o fato de muitas pessoas encontrarem-se empregadas em atividades familiares ou de pequena escala nos países subdesenvolvidos (McGEE, 1977). A este quadro somava-se a tomada de consciência do fracasso do modelo de integração apoiado no desenvolvimento industrial, diante do forte aumento da pobreza urbana e do subemprego massivo nestes países.

A conformação desta nova realidade urbana e social suscitou, então, o surgimento de distintas interpretações teóricas sobre o processo de urbanização do Terceiro Mundo e suas características. Neste contexto, emergiram as diferentes vertentes da teoria da modernização, a qual postulava, grosso modo, a diferenciação entre dois setores distintos nos países periféricos: de um lado um setor moderno e, de outro lado, um setor tradicional (BOEKE, 1953; LEWIS, 1954; GEERTZ, 1963). O modelo dualista, no qual reside também a origem da categoria de setor informal, assumiu, ao longo dos anos seguintes, progressivamente o valor de paradigma (KUHN, 1962) para pensar as realidades urbanas dos países subdesenvolvidos. Ao mesmo passo, o setor informal tornou-se um “objeto legítimo" de políticas e de pesquisas (LAUTIER, 1994).

No entanto, a partir de meados da década de 1970, o modelo dualista e o uso da categoria setor informal foram também fortemente questionados. Autores como Quijano (1972), McGee (1977) e Slater (1982), apontavam as limitações de sua fundamentação na dicotomia tradicional versus moderno e a desconsideração das interações entre os ditos setores da sociedade, reduzidos ao fluxo de mão-de-obra de um para outro. A teoria dos dois circuitos da economia urbana nos países subdesenvolvidos, proposta por Milton Santos em meados da década de 1970 (SANTOS, 1975), destacou-se dentre as abordagens críticas à teoria dualista. Com esta teoria, o autor visava então a uma análise da urbanização do Terceiro Mundo que levasse em conta tanto sua dimensão histórica quanto a especificidade de seu espaço. Tendo em vista que as cidades abrigam diferentes divisões do trabalho que coexistem e que estabelecem relações diferenciadas com o meio construído; Santos propôs compreender estas divisões do trabalho coexistentes como circuitos da economia urbana que se distinguem em função dos diversos graus de tecnologia, capital e organização assumidos pelas atividades urbanas. Quando estes são altos, trata-se do circuito superior, incluindo sua porção marginal; quando são baixos, trata-se do circuito inferior.

Composto pelos bancos, comércio e indústria de exportação, indústria moderna, serviços modernos, atacadistas e transportadores, o circuito superior compreende o resultado direto das modernizações que atingem o território. $\mathrm{O}$ circuito inferior, por sua vez, constitui o resultado indireto da modernização e abarca as formas de fabricação não-capital intensivo, serviços não modernos fornecidos a varejo, comércio não moderno e de pequena dimensão, voltados sobretudo ao consumo da população de baixa renda. Conforme explica Santos (1975), os circuitos não constituem, todavia, sistemas fechados, já que se encontram interligados por intensas relações de complementaridade, concorrência e subordinação. Compreendem, em realidade, subsistemas do sistema urbano, no qual todas as formas de trabalho encontram-se integradas (SILVEIRA, 2011).

Inspirados pelo potencial analítico da teoria dos circuitos, diferentes pesquisadores têm realizado um esforço de releitura e atualização desta teoria à luz dos novos processos que permeiam a economia urbana no período atual (SILVEIRA, 2007, 2009, 2010, 2011; BICUDO JR., 2006; OLIVEIRA, 2010; DI NUCCI, 2010; DAVID, 2010; MONTENEGRO, 2011; SILVA, 2012). Trazemos aqui certas contribuições nesse sentido, ao apresentar resultados de nossas pesquisas recentes 
sobre os dinamismos atuais do circuito inferior nas metrópoles brasileiras e sobre os novos nexos estabelecidos entre os circuitos da economia urbana no período da globalização.

Nos dias de hoje, há uma expansão substancial do volume do circuito inferior nas maiores cidades do país. Contudo, para além desta expansão quantitativa, verifica-se também uma intensa renovação de suas dinâmicas e de suas relações com o circuito superior. Os limites entre os circuitos da economia urbana se realizam em novos termos, redefinindo, por conseguinte, o valor relacional e dialético entre eles.

\section{METROPOLIZAÇÃO DA POBREZA E EXPANSÃO DO CONSUMO}

Os dinamismos da economia pobre nas metrópoles brasileiras têm se tornado, nos dia de hoje, crescentemente complexos, haja vista a conformação de um cenário paradoxal em que a expansão do consumo entre as camadas de baixa renda se combina ao aumento da pobreza. Ao longo dos últimos anos, verificou-se uma redução na porcentagem de pobres entre a população brasileira, a qual recuou de 38,6\% em 2001 para 20,6\% em 2011 (IBGE/ PNAD, 2011). Tendo em vista que o valor do salário mínimo representa o principal indicador para estimativa da pobreza no país , observa-se que esta redução decorreu, em grande medida, do efeito estatístico do aumento do salário mínimo na última década: o qual passou de $\mathrm{R} \$ 151,00 \mathrm{em} 2001$ para $\mathrm{R} \$ 545,00 \mathrm{em} 2011$. Apesar do reajuste ocorrido, cabe ressaltar que o salário mínimo vigente em 2013 - de R\$ 678,00 - estava ainda a uma enorme distância do valor do salário mínimo considerado necessário - de R \$ 2.674,88 - para atender as necessidades vitais básicas no país nesta data (DIEESE, 2013).

Por outro lado, embora a pobreza venha se reduzindo nas áreas rurais, tem se tornado cada vez mais um fenômeno urbano e metropolitano no país (ROCHA, 2006; 2009). Enquanto a participação dos indigentes e dos pobres rurais no total destes segmentos vem se reduzindo, a participação urbana e metropolitana cresceu significativamente no país nos últimos anos . A crescente aglomeração da população em grandes cidades, traduzida pelo avanço da urbanização e da metropolização, tem sido acompanhada, assim, pela concentração da pobreza nas metrópoles brasileiras (IBGE, 2010). Pois, a despeito do que apontam certos indicadores para o conjunto do país, a pobreza está, em realidade, se aprofundando nas metrópoles, visto que ao longo da última década ocorreu, efetivamente, um aumento na proporção dos domicílios com renda per capita até $1 / 2$ salário mínimo em todas as Regiões Metropolitanas (IBGE/PNAD, 2003, 2007, 2009).

Por outro lado, verifica-se que esta mesma população que se empobrece também tem participado, cada vez mais, de um consumo moderno. Nos últimos anos, a expansão do acesso a artefatos como telefones celulares e computadores, assim como a serviços de telecomunicações em geral, vem sendo acompanhada também pela ampliação do acesso a certos bens duráveis (geladeira, máquina de lavar, televisão, rádio etc) entre a população pobre metropolitana. Entre as famílias com renda per capita até $1 / 2$ salário mínimo residentes nas Regiões Metropolitanas , o acesso a geladeiras passou de $69 \%$ em 1995 para $88 \%$ em 2004, já o acesso a máquinas de lavar cresceu de $8 \%$ para 18\% neste mesmo período (TORRES et alli, 2006). Considerado o total de domicílios do país, verifica-se que em 2011, 96\% dos lares possuíam geladeiras, 98,5\% fogão e 96,8\% televisão (IBGE/ PNAD, 2011). Apenas no intervalo entre 2007 e 2013, a quantidade de acessos de telefonia móvel passou de 120,9 milhões a 263 milhões, dos quais atualmente 80,2\% funcionam na modalidade "pré-pago", adotada sobretudo pela pelo estrato de menor renda (ANATEL, 2013).

Este aumento recente do consumo em meio à população de baixa renda no Brasil está relacionado a um amplo conjunto de fatores (TORRES et alii, 2006; NERI, 2011; MONTENEGRO, 2011). Dentre estes, destacam-se, em diferentes medidas, o papel das políticas públicas federais de transferência de renda; o reajuste do valor do salário mínimo; uma menor variação na estrutura de preços; a redução do tamanho da família no país; a crescente participação feminina no mercado de trabalho e a maior oferta de crédito. Em meio a esta combinação de fatores, acreditamos que aquele que exerce uma influência decisiva na expansão do consumo entre as camadas de baixa ren- 
da residentes nas metrópoles seja o aumento da oferta de crédito nos últimos anos. Vale destacar, nessa direção, que os recursos do Programa Bolsa Família beneficiam principalmente municípios de pequeno porte localizados nas Regiões Norte e Nordeste (MDS, 2012).

Entre 1997 e 2012, o volume da concessão de crédito pessoal no Brasil passou de R \$ 50 bilhões para mais de R $\$ 304$ bilhões. O aumento da quantidade de cartões (crédito, débito e de lojas) no país aparece como um indicador revelador deste processo: entre 2000 e 2010, o número de cartões cresceu mais de 520\%, saltando de 119 milhões para 628 milhões de unidades (ABECS, 2010).

O avanço do endividamento e da inadimplência compõe, todavia, o reverso deste cenário de creditização da população: atualmente cerca de 83 milhões de brasileiros possuem dívidas no cheque especial, no cartão de crédito ou junto às agências financeiras (SERASA, 2010), cifra que equivale a 52\% da População Economicamente Ativa (PEA) do país. Entre 1999 e 2005, a quantidade de títulos não pagos aumentou aproximadamente 110\%; ao mesmo passo, o volume de crédito pessoal cresceu cerca de 290\% (SERASA, 2006). Desde 2009, a inadimplência do consumidor no país aumentou mais de 51,5\%; e em 2012, a inadimplência total atingiu o maior patamar da série calculada desde 2000 (BANCO CENTRAL, 2012; SERASA, 2013). Verifica-se, assim, que a expansão da oferta de crédito e a ampliação do acesso a certos objetos técnicos não têm levado à eliminação da situação de pobreza nas grandes cidades. O aumento da oferta de crédito vem sendo igualmente acompanhado pelo avanço do endividamento e da inadimplência; implicando, por conseguinte, a reprodução da pobreza em novos termos.

\section{ALARGAMENTO DO CIRCUITO INFERIOR METROPOLITANO}

No período atual, observa-se também um rearranjo nas dinâmicas dos mercados de trabalho metropolitanos no Brasil. Ao mesmo passo em que as grandes empresas do circuito superior, graças às modernizações técnicas e organizacionais, tornam-se menos empregadoras; o circuito inferior se afirma como o principal provedor de ocupação e renda à população pobre metropolitana. Destarte, o aumento da pobreza e a multiplicação das formas de trabalho do circuito inferior nas grandes cidades constituem parte do mesmo processo de reprodução estrutural da pobreza no país.

Desde os anos 1990, confirma-se, efetivamente, uma tendência de deslocamento das ocupações de grandes empresas, que se tornam cada vez mais poupadoras de mão-de-obra, para as micro e pequenas empresas (SEBRAE, 2000; POCHMANN, 2010). Dentre as ocupações criadas nos últimos anos, constata-se que a maioria foi gerada por pequenas empresas, especialmente por aquelas ditas de baixa "produtividade", pouco exigentes em relação à qualificação e que oferecem menor remuneração (COMIN, 2003; POCHMANN, 2010). Em 2010, as micro empresas totalizavam mais de 4,59 milhões de estabelecimentos; somadas as micro e pequenas empresas possuíam, então, uma participação de quase $99 \%$ do total de empresas formais no país, enquanto as maiores representavam apenas 0,3\% desse universo (IBGE, 2010). Segundo Pochmann (2010), mais de dois terços dos empregos formais gerados na última década no Brasil provêm destes micro e pequenos negócios.

Embora a média de ocupados por unidade ou estabelecimento do circuito inferior seja baixa, ele acaba por exercer um efeito de compensação sobre o mercado de trabalho em função da infinidade de pequenas atividades que fornecem ocupação e renda para grande parte da população pobre concentrada nas grandes cidades. Neste sentido, a adesão de mais de 2,5 milhões de pessoas à figura jurídica do Micro Empreendedor Individual (MEI) nos últimos anos também revela a dimensão do universo extremamente diverso das atividades realizadas com poucos recursos. Dentre os pequenos negócios que aderiram ao estatuto do MEI, destacam-se os comércios varejistas de artigo de vestuário, salões de cabeleireiros, minimercardos, mercearias e lanchonetes e similares (SEBRAE, 2011).

Todavia, é preciso atentar ao fato de que os dados destacados se referem apenas às empresas e atividades com registro formal, ou seja, aquelas que possuem uma existência legal, um código de registro no Cadastro Nacional de Pessoa Jurídica (CNPJ), ou aquelas que aderiram à figura jurídica do Micro Empreendedor Individual (MEI). Logo, podemos afirmar que o número de micro 
negócios é consideravelmente superior aqueles disponíveis. Tais cifras abrangem apenas uma parte da economia urbana e não revelam a magnitude da economia das metrópoles e sua relação com a pobreza. Há toda uma economia urbana que não cabe nessas classificações que, por sua vez, não coincidem integralmente com a realidade abrangida pelo conceito de circuito inferior que se define, por sua vez, pelos reduzidos graus de tecnologia, capital e organização das mais diversas formas de trabalho. Ademais, é importante frisar que as classificações de micro e pequenas empresas são definidas em função do número de funcionários e não de seu nível de capitalização, englobando, portanto, inclusive pequenas empresas que podem ser altamente capitalizadas.

Neste contexto de rearranjo da divisão do trabalho intra-urbana, grande parte da população das metrópoles brasileiras vem encontrando suas oportunidades de trabalho e de geração de renda no circuito inferior, onde a mobilização de um baixo grau de capital permite a criação de um número significativo de postos de trabalho (SILVEIRA, 2007). A dilatação da chamada capacidade auto-inflacionária do circuito inferior (McGEE, 1971) aparece aí como um dos principais indicadores de sua expansão. Pesquisas realizadas em São Paulo, Brasília, Fortaleza e Belém nos revelam como a fragmentação extrema das tarefas, que permite a multiplicação das ocupações, se reafirma como uma das principais manifestações desta capacidade auto-inflacionária da economia pobre nos dias de hoje.

As feiras e os mercados populares configuram situações especialmente emblemáticas deste fenômeno em que se somam ou se subdividem atividades de vendedor, ajudante, carregador de mercadorias, montador de barracas, abastecedor etc. Por um lado, a subdivisão de funções intermediárias permite a ampliação da quantidade de ocupações e da capacidade de geração de ocupação e renda do circuito inferior. Por outro lado, contudo, a fragmentação extrema das tarefas implica igualmente o fracionamento do capital disponível. Os níveis de remuneração dos trabalhadores do circuito inferior nas metrópoles brasileiras apontam para o grau de carência de capital que define o cotidiano destes agentes: dentre cerca de 300 trabalhadores do circuito inferior entrevistados em São Paulo, Brasília, Fortaleza e Belém, 45\% têm um rendimento mensal inferior a 1,5 salário mínimo.

A combinação de atividades não relacionadas entre si em um mesmo estabelecimento, envolvendo muitas vezes o compartilhamento dos benefícios e dos custos de uma localização, se destaca, também, entre as atuais manifestações da capacidade auto-inflacionária que define a divisão do trabalho no circuito inferior. Donde a multiplicação de bancas de jornal que oferecem o serviço de conversão de fita K7 e LP para CD, chaveiros que vendem bijuterias e biscoitos, relojoarias em que são comercializados cosméticos, salões de cabeleireiro onde se anuncia a conversão de vídeos VHS para DVD etc. Encontramos aí situações em que capitais e trabalhos diferentes se associam para garantir o acesso ao mercado e aos efeitos úteis de aglomeração (TOPALOV, 1979), concentrados em determinadas localizações.

A adaptabilidade e a criatividade, características inerentes ao circuito inferior, expressam como a "flexibilidade tropical" (SANTOS, 1996) pode garantir ocupação e renda à grande parte da população que vive nas grandes cidades. Haja vista a "multiplicidade de combinações em movimento permanente, dotadas de grande capacidade de adaptação, e sustentadas no seu próprio meio geográfico, este sendo tomado como uma forma-conteúdo, um híbrido de materialidade e relações sociais" (SANTOS, 1996, p.220). Surgidos de necessidades existenciais, multiplicam-se, assim, os mais diversos tipos de trabalhos, voltados à satisfação de demandas insatisfeitas de um mercado pobre que busca participar, cada vez mais, dos modelos de consumo das camadas de alta renda. Estas atividades tendem, muitas vezes, a não seguir parâmetros e normatizações, das quais dificilmente tomam conhecimento (SILVEIRA, 2007).

Um dos registros mais fiéis da presença do circuito inferior nas metrópoles brasileiras reside na diversidade e na desvalorização de certas parcelas do meio construído (OLIVEIRA, 2009). Áreas menos valorizadas nas centralidades populares e periferias dos bairros pobres concentram a maior densidade das atividades da economia popular, visto que os recursos da maioria de seus agentes lhes permitem a inserção somente nestas localizações. Segundo Silveira (2010), a condição 
oligopolista da cidade é um processo que não se completa, uma vez que há interstícios - na divisão das tarefas e no meio construído - que não interessam ao circuito superior. E são justamente estes espaços intersticiais do tecido urbano e da divisão social do trabalho que sustentam a presença e a ampliação do circuito inferior. Ao mesmo tempo em que o circuito superior expande seu controle sobre o território, privilegiando as áreas aptas aos seus interesses, se distancia das atividades banais realizadas na cidade.

\section{DA RENOVAÇÃO DOS DINAMISMOS DA ECONOMIA POPULAR E DE SUAS RELAÇÕES COM AS VARIÁVEIS CHAVE DO PERÍODO DA GLOBALIZAÇÃO}

Para além da expansão quantitativa do circuito inferior, verifica-se, no período atual, uma intensa renovação de seus dinamismos e de suas relações com o circuito superior; uma vez que a pobreza atual, de caráter estrutural, é uma pobreza da globalização. Neste sentido, a pobreza não deve ser entendida como um fenômeno "a-histórico", assim como a economia pobre não deve ser vista como "tradicional" e estática. As constantes vagas de modernização impactam os modelos de consumo e a economia urbana das cidades, e neste processo, as ocupações ditas "tradicionais" são chamadas, constantemente, a desempenhar novos papéis (SANTOS, 1978), reformulando-se frente à nova composição de forças que distingue cada momento histórico.

Por um lado, encontramos no circuito superior os próprios motores da mais nova divisão territorial do trabalho que se pauta sobre conteúdos intensivos em técnica, informação e finanças, ou seja, sobre as variáveis determinantes da globalização. Contudo, no período atual, essas mesmas variáveis tornam-se também dominantes (SANTOS, 1996), na medida em que atingem e remodelam as demais divisões territoriais do trabalho, ou seja, os circuitos inferior e superior marginal.

Multiplicam-se, hoje, as relações estabelecidas atualmente entre o circuito inferior e as variáveis chave do período da globalização - entendidas como a técnica, a informação, o consumo e as finanças - e intensificam-se, por conseguinte, as transformações da economia pobre nas maiores cidades brasileiras. Esta crescente difusão e assimilação das possibilidades da época atual entre os atores não hegemônicos podem ser entendidas, justamente, como parte do processo de transformação destas variáveis determinantes em variáveis dominantes.

Como vimos acima, o aumento exponencial das práticas de consumo tem assumido dimensões cada vez mais abrangentes no território brasileiro, envolvendo todas as classes de renda. No período atual, o consumo adquire, com efeito, um papel crescentemente determinante nas dinâmicas sociais. Na leitura de Bauman (2007), viveríamos hoje em uma "sociedade de consumidores" pautada pela "refundação" das relações humanas à medida dos mercados; sendo a característica mais proeminente da sociedade atual justamente sua capacidade de comprometer seus membros como consumidores. Ao analisarem as relações atuais entre geografia e consumo, Ballesteros e Carreras (2006, p.326), destacam, nesta direção, que o consumo é a "(...) a perspectiva mais importante a partir da qual se deve entender a nova diferenciação das classes sociais, distanciando-se da explicação clássica relativa à propriedade dos meios de produção".

O processo de expansão do consumo e do aumento do crédito aos pobres nas grandes cidades brasileiras envolve, direta ou indiretamente, tanto o circuito superior quanto o circuito inferior da economia urbana. Por um lado, os pequenos negócios do circuito inferior buscam responder ao aumento do consumo, diversificando serviços e produtos oferecidos, muitas vezes inspirados naqueles do circuito superior. Por outro lado, o circuito superior da economia apresenta-se cada vez mais interessado no nicho de mercado popular das chamadas classes C, D e E, ou seja, naquela parcela do mercado tradicionalmente pertencente ao circuito inferior da economia. Nos últimos anos, a creditização da população de baixa renda vem garantindo, de fato, a inserção desta parcela no mercado consumidor das grandes redes do circuito superior que coincidem, por sua vez, com os catalisadores da expansão recente do crédito no país. No bojo deste processo, estabelecem-se complexas formas de associação entre grandes cadeias comerciais de varejo, bancos e suas respectivas 
instituições financeiras de crédito pessoal, constituídas, em grande medida, para abarcar os pobres no mercado de consumo (SILVEIRA, 2009; LOPES dos SANTOS, 2007).

Assim, além de criar a demanda e incitá-la através de uma propaganda altamente sofisticada que impele ao consumismo, as grandes empresas têm adotado também uma estratégia de financeirização e endividamento dos novos consumidores em potencial. Revigora-se, por conseguinte, a combinação entre uma publicidade que ativa o mercado e um crédito que catalisa o consumo (LOPES dos SANTOS, 2007). Daí a multiplicação de novas gamas de produtos e serviços voltados especialmente às parcelas do mercado de menores rendimentos que anseiam pelo acesso às marcas mais conhecidas. Conforme coloca Sennet (2006), a exaltação das marcas e da suposta potência embutida nos objetos assumem, no período atual, um papel cada vez mais determinante na paixão do consumidor pelo consumo. $\mathrm{O}$ acesso crescente das camadas de baixa renda a estes bens e serviços se realiza sobretudo através de formas de pagamentos parcelados, nas quais não deixam de estar embutidos altíssimos juros.

A diversificação de suas topologias configura outra estratégia recentemente adotada pelas maiores empresas para alcançar os consumidores de baixa renda nas grandes cidades. Agências financeiras de crédito pessoal, lojas de departamento, vestuário e eletrodomésticos, entre outras, têm multiplicado suas filiais em centralidades populares, onde buscam aproveitar-se da circulação intensa que estas áreas abrigam. Contudo, a nova topologia do circuito superior vem englobando também localizações consideradas relativamente desinteressantes até então pelas maiores empresas. Grandes equipamentos de consumo - como shopping-centers, supermercados, hipermercados e lojas e serviços sob sistemas de franquias - têm migrado para bairros periféricos de metrópoles como São Paulo e Brasília. Além de concentrar um enorme mercado pobre, que hoje tem acesso ao crédito desburocratizado, estas periferias reúnem também grandes superfícies disponíveis.

A presença de estabelecimentos desta natureza em bairros pobres figura, assim, entre os fatores que contribuem para que as práticas de compras dos pobres se distribuam, cada vez mais, entre a oferta de grandes redes globais, agora presentes também nas periferias, e o pequeno comércio (DUHAU e GIGLIA, 2007). Uma vez que os circuitos da economia urbana se definem tanto pelas atividades desenvolvidas quanto pelos estratos da população que se ligam a eles pela realização da atividade e pelo consumo (SANTOS, 1978), diversificam-se, por conseguinte, as relações entre eles.

Conformam-se, hoje, novas articulações entre o circuito inferior, ou seja, entre a população que consome e trabalha majoritariamente nesse circuito, e as grandes empresas do circuito superior, como os bancos e suas instituições de crédito pessoal, as grandes redes de varejo e serviços. Configuram-se, na realidade, novas formas de interferência do circuito superior no circuito inferior, as quais alavancam a drenagem de dinheiro, já escasso, do último para o primeiro. O consumo crescente da população pobre junto às grandes redes significa, por fim, uma subtração da demanda e a perda de mercados do circuito inferior para o circuito superior.

\section{NOVOS CRIVOS ENTRE OS CIRCUITOS DA ECONOMIA URBANA}

As variáveis determinantes do período atual permeiam a economia pobre de forma cada vez mais inter-relacionada, implicando a renovação dos laços de subordinação e complementaridade entre os circuitos da economia. As finanças, por exemplo, se "capilarizam" pela economia pobre por diferentes canais. Como vimos acima, a expansão da oferta de um crédito cada vez mais desburocratizado a uma população sem lastro tem implicado não apenas um aumento do endividamento e a inadimplência entre esse estrato da população, mas igualmente uma redefinição de suas práticas de consumo.

Por outro lado, a crescente difusão e a incorporação de terminais eletrônicos de cartões de débito e de crédito (conhecidos como "maquininhas") como forma de pagamento entre os pequenos negócios configura outro fenômeno especialmente revelador da permeabilidade alcançada pelas finanças no circuito inferior. Estes meios eletrônicos de pagamento são emitidos por bancos e outras instituições 
financeiras, dentre as quais se destacam as marcas globais das organizações de cartões denominadas "bandeiras". Nas grandes cidades, a incorporação dos cartões de débito e de crédito como forma de pagamento ocorre nos mais diferentes tipos de estabelecimentos do circuito inferior. Pequenos salões de cabeleireiro, papelarias, chaveiros, relojoeiros, oficinas e vendinhas vêm adotando, desde 2002, progressivamente os terminais eletrônicos em seus negócios. Dentre os estabelecimentos do circuito inferior entrevistados no centro de São Paulo, por exemplo, os cartões de débito configuram o principal meio oferecido pelos pequenos negócios entrevistados, além do dinheiro em espécie. O fiado, por sua vez, vem perdendo espaço entre os pequenos negócios localizados nas áreas centrais das grandes cidades. Os nexos financeiros parecem se instalar aí com mais voracidade do que na periferia, onde o fiado ainda se mantém como uma característica típica do pequeno comércio de bairro, podendo representar, em certos casos, inclusive a prática mais adotada .

A adoção de terminais eletrônicos para cartões representa um meio dos pequenos negócios diversificarem as formas de pagamento oferecidas e, portanto, abarcarem uma maior parcela do mercado consumidor. O uso das "maquininhas" permite ainda reduzir os impactos da inadimplência em comparação a outros meios de pagamento, como o cheque, por exemplo, e pode funcionar também como um instrumento de antecipação de crédito junto aos bancos . Por outro lado, a incorporação dos terminais eletrônicos representa o comprometimento com altos custos operacionais para os pequenos negócios: além de mensalidades pagas pelo aluguel das máquinas, são cobradas também porcentagens sobre o valor de cada transação realizada através das mesmas. Há ainda o custo da linha telefônica, tanto no caso dos terminais fixos, quanto no caso dos terminais móveis que funcionam através de redes de telefonia celular e de radiofreqüência. Entre os pequenos negócios do circuito inferior localizados nas grandes cidades, as mensalidades pagas pelo aluguel dos terminais variam na faixa de $\mathrm{R} \$ 50,00$ a $\mathrm{R} \$ 60,00$ e as taxas cobradas sobre o valor das operações de débito e crédito vão de $2 \%$ a $5 \%$. A incorporação das "maquininhas" para o pagamento com cartões provoca, deste modo, uma aceleração da drenagem da poupança popular para o circuito superior, uma vez que se multiplicam os canais que a conduzem. À subordinação financeira, acresce-se ainda uma dependência técnica, haja vista a imposição do uso exclusivo dos terminais eletrônicos de empresas autorizadas pelas bandeiras de cartão de crédito.

Nesta direção, a incorporação de certas técnicas modernas entre os agentes da economia popular se destaca como outro fenômeno emblemático da renovação dos dinamismos do circuito inferior da economia no período atual. Aparelhos de telecomunicações como telefones celulares, equipamentos de fotocópia, vídeo e fotografia, assim como os computadores, entre outros, tornaram-se mais acessíveis aos agentes do circuito inferior e passaram a permear seu cotidiano tanto na esfera do consumo, como do trabalho. A ampliação do acesso a estas novas técnicas, que se tornaram mais acessíveis graças ao seu relativo barateamento e ao crédito, vem engendrando, por sua vez, o constante surgimento de novos afazeres possíveis; revelando-nos como a criatividade sempre renovada "atualiza" e permeia o circuito inferior; ainda que esta incorporação venha acompanhada de novos nexos de dependência e de subordinação. Multiplicam-se hoje os serviços de fotocópia, de acesso à internet (lanhouses), de formatação de currículos e criação de contas de e-mail; de venda, troca e consertos de artigos novos e usados de informática; de venda de chips de telefones celulares, pendrives, cartuchos "recauchutados", CDs, DVDs, games, chips de celular, baterias, cartões de memória; de recarga de tonners e de cartuchos de tinta de impressora; de compra, venda e assistência técnica de vídeo games, de conserto de telefones etc.

Novas relações de concorrência e complementaridade entre os circuitos da economia urbana se estabelecem justamente em torno das atividades de conserto, ramo que concentra milhares de pequenas oficinas do circuito inferior . Por um lado, estas oficinas de reparo sofrem cada vez mais a concorrência das chamadas "assistências técnicas" de marcas autorizadas e dos serviços pós-vendas de grandes empresas. Por outro lado, não deixam de garantir a circulação de produtos oriundos do circuito superior, uma vez que procuram ampliar a gama de serviços oferecidos a estes 
artigos. As pequenas oficinas de conserto sofrem ainda as conseqüências dos fenômenos de redução da longevidade dos objetos e de aceleração do descarte (GAUDIN, 1978; BAUMAN, 2007) que acompanham a expansão do consumo. Não obstante, a tendência de que o mercado de renovação substitua o mercado de reparação nunca se realiza completamente. A maioria da população não pode participar do consumo em moldes acelerados de substituição e descarte, logo, o mercado para as atividades de consertos não deixa de se reproduzir.

Ao garantir a distribuição de aparatos técnicos modernos, oriundos de grandes empresas, junto aos consumidores de baixa renda e ao oferecer serviços de reparo a esses mesmos produtos, o circuito inferior acaba por exercer um papel ativo na difusão do sistema técnico da globalização. Participa, assim, da conformação da unicidade técnica, a qual não se caracteriza, no entanto, pela presença exclusiva de uma única técnica (SANTOS, 1996). Em outras palavras:

Tanto pela expansão dos novos produtos, amiúde tornados instrumentos de trabalho em atividades não hegemônicas, como pela proliferação de atividades de conserto que permitem a reutilização de bens, ou mesmo pela distribuição tantas vezes desinteressante para os grandes capitais, os circuito superior marginal e inferior participam, de forma crescente e por vezes contraditória, da produção da unicidade técnica (SILVEIRA, 2011, p.67).

A incorporação de certas tecnologias modernas como instrumento de trabalho em pequenos negócios vem permitindo, ademais, a realização de publicidade através de novos meios, como a internet. As formas de propaganda adotadas atualmente pelo circuito inferior nas metrópoles brasileiras se diversificam, cada vez mais, para além do "boca a boca"; visto que a sofisticação da publicidade realizada pelas grandes empresas e o aumento da concorrência por parcelas do mercado popular lhes impõem a necessidade de divulgar suas atividades através de folhetos, cartões de visita, faixas, banners e da própria internet. Em muitos casos, a elaboração destas formas de propaganda envolve custos, seja através de sua terceirização para gráficas ou de sua elaboração pelos próprios pequenos estabelecimentos. Se em um período anterior o circuito inferior não despendia gastos com a publicidade, hoje esse tipo de custo assume uma importância crescente em sua contabilidade.

Diante da velocidade assumida pelo progresso técnico no período atual, o processo de incorporação das técnicas materiais e imateriais do período torna-se mais acelerado entre os agentes não-hegemônicos. Contudo, a modernização sempre renovada da técnica realizada no âmbito do circuito superior tende a ampliar, continuamente, a distância entre os circuitos. $\mathrm{O}$ alto nível de especialização de certas técnicas, combinado a uma normatização mais rígida, permite usos cada vez mais precisos entre as maiores empresas e assim, enquanto, aprofunda-se a hipertelia (SIMONDON, 1958) da técnica no âmbito do circuito superior; o acesso às tecnologias mais banais do período difunde-se entre os agentes do circuito inferior.

A incorporação das técnicas modernas entre as atividades da economia popular permite definir o circuito inferior como atividades pouco capitalizadas que apresentam um menor grau de tecnologia, mas não sua ausência completa. Por outro lado, um dos principais critérios que diferencia os circuitos hoje é justamente o grau de organização embutido nas técnicas materiais e imateriais, e não mais o acesso à tecnologia em si. No período atual, a inserção na divisão territorial do trabalho hegemônica exige não apenas um grau de capital e uma tecnologia própria ao sistema técnico vigente, mas também uma forma de organização específica (SILVEIRA, 2011).

Assim, ao mesmo passo em que o sistema técnico atual se banaliza entre os agentes do circuito inferior, o grau de organização embutido nas técnicas adotadas pelos circuitos tende a se diferenciar cada vez mais. A organização, que envolve a profusão de normas e uma densa burocratização, assume uma crescente importância enquanto crivo de diferenciação entre os circuitos. "Bens organizacionais", produzidos por consultorias financeiras e de serviços avançados, são cada vez mais demandados pelas maiores empresas (SASSEN, 2003). No bojo deste processo, a "variável relacional" adquire um papel central na divisão do trabalho inter e intra empresarial no circuito superior envolvendo, por sua vez, um enrijecimento das normas técnicas e a multiplicação de normas 
socioorganizacionais (VELTZ, 1999). A sofisticação da organização e da normatização no circuito superior se contrapõe ao predomínio de uma organização desburocratizada e à ausência de rigidez na divisão e realização das tarefas no circuito inferior.

O grau de capitalização entre os circuitos da economia urbana também tende a se distanciar cada vez mais. No período atual, cresce enormemente a disparidade entre os coeficientes de capital, fixo e de giro, das atividades e das empresas dos circuitos inferior e superior. A ampliação da capacidade de geração de ganhos e a crescente rentabilidade das finanças e dos serviços avançados, revelados pela própria financeirização da riqueza, contrastam com a escassez de capital que define o cotidiano da maioria das atividades urbanas. Toda uma "economia dos centavos" (MONTENEGRO, 2011) segue sendo determinante para o orçamento de milhares de pequenos negócios localizados nas cidades brasileiras.

Uma miríade de atividades revela o quanto o dinheiro pode e deve "render" entre trabalhadores e consumidores do circuito inferior. Em bairros pobres e populosos de cidades como Belém e Fortaleza, este fenômeno manifesta-se em diversas situações, como, por exemplo, no pagamento de centavos pelo uso da internet em lanhouses (pagamento pela fração de hora), na venda de "dindin" fresco por R $\$ 0,25$ (ou da versão cremosa por R \$ 0,30), na venda de balas e chicletes, em bicicletarias onde se enchem os pneus murchos por R \$ 0,25 , entre outras. A fragmentação das tarefas se combina, em certos casos, ao fracionamento das mercadorias (comprimidos, doces e cigarros avulsos) e, por conseguinte, ao fracionamento do capital que circula, constantemente, na forma de moedas. Haja vista o baixo poder de compra dos consumidores, cada cliente só pode comprar quantidades pequenas ou demandar serviços relativamente baratos. Nesta direção, cabe destacar que embora a possibilidade de pagamento com cartões de débito e de crédito venha se difundindo recentemente no circuito inferior, o dinheiro à vista se mantém como a principal forma de circulação monetária entre os agentes deste circuito nas metrópoles brasileiras.

Deste modo, se por um lado, reduz-se a distância entre os circuitos no que tange à tecnologia; por outro lado, aumenta a polarização em relação aos níveis de capitalização e organização. Não obstante, mesmo que o circuito inferior tenha maior acesso ao crédito e passe a incorporar certos objetos técnicos em suas atividades, a modernização sempre renovada da técnica e o grau de organização embutido nas novas tecnologias o impedem de acompanhar o compasso da modernização tecnológica.

Assim, embora observemos hoje certo rearranjo no peso entre as variáveis que definem os circuitos da economia urbana, a combinação destes fatores revela, em realidade, um aumento da distância entre eles (SILVEIRA, 2011). Revigora-se, neste sentido, a necessidade de pensar o valor relacional entre os circuitos da economia urbana, visto que o limite entre eles também se renova a cada momento.

A análise das relações do circuito inferior com as variáveis chave do período atual nas metrópoles brasileiras revela diferentes processos de adaptação e resistência por parte da economia pobre; evidenciando, por fim, o caráter dialético desta dinâmica, em que se combinam a necessidade e a impossibilidade de acompanhar o passo da modernização atual. A capacidade de ajustamento do circuito inferior às transformações conjunturais do momento deve renovar-se constantemente, pois enquanto o circuito superior tende a criar a conjuntura, "o circuito inferior só pode funcionar através de uma adaptação estreita às condições conjunturais" (SANTOS, 1978, p.253).

Além disso, embora possamos afirmar que haja, de fato, um uso crescente das variáveis chave da globalização por parte dos agentes do circuito inferior, acreditamos que este processo também deva ser visto de forma dialética. Pois se, por um lado, as cidades abrigam diferentes formas de incorporação destas variáveis pela economia pobre; por outro lado, tal assimilação não deixa de representar novas formas de subordinação ao circuito superior. 


\section{CONSIDERAÇÕES FINAIS}

De modo geral, o circuito inferior encontra-se, efetivamente, cada vez mais impactado e permeado pelos nexos do período da globalização. Processos como a diversificação das práticas de consumo, a financeirização da pobreza, a incorporação de novas tecnologias, a difusão da informação e o avanço progressivo do circuito superior sobre as parcelas do mercado e do meio construído tradicionalmente pertencentes a este circuito, se fazem presentes, hoje, em todas as metrópoles do país. Contudo, estes processos vêm implicando, certamente, o aprofundamento da subordinação e da dependência do circuito inferior face ao circuito superior em novos patamares.

Por outro lado, estes fenômenos, de caráter mais geral, assumem manifestações e densidades particulares em cada cidade, visto que os dados do período da globalização se instalam nos lugares de formas distintas, com intensidade variável e através de diferentes nexos (SILVEIRA, 2006). Por conseguinte, a forma como o meio técnico-científico-informacional alcança as regiões é diferencialmente produtora de pobreza e implica, por sua vez, uma adaptação, uma reformulação diferenciada do circuito inferior segundo a região e a cidade. Conforme afirma Santos (1996), as possibilidades do período são filtradas pela formação socioespacial, e se combinam aos conteúdos preexistentes em cada lugar, reformulando constantemente suas existências.

No território brasileiro, as cidades nos revelam, com diferentes densidades, como os limites entre os circuitos da economia urbana se realizam atualmente em novos termos e como o circuito inferior vem passando por um intenso processo de renovação de seus dinamismos. No entanto, é preciso reafirmar que apesar desta intensa reconfiguração, o circuito inferior segue pautando-se pela reprodução da pobreza e pela busca da sobrevivência cotidiana.

Em um período marcado pela consolidação das finanças como sua variável determinante, pelo avanço da oligopolização da economia e pela conformação de uma esfera normativa baseada nos preceitos do mercado, o maior desafio continua a ser o enfrentamento da pobreza estrutural. Tendo em vista que circuito inferior e pobreza são sinônimos (SANTOS, 1975), este desafio consiste, em grande medida, em torná-lo menos subordinado ao circuito superior, assim como em expandir as oportunidades e proteções aos agentes do circuito inferior da economia, valorizando seus dinamismos e particularidades. Nesta direção, revigora-se a importância de aprofundarmos a compreensão do conteúdo geográfico do cotidiano da maioria (SANTOS, 1996), ou ainda, de realizarmos, como propunha Dardel (1952), uma geografia voltada à busca do entendimento de como o homem realiza sua existência.

\section{REFERÊNCIA BIBLIOGRÁFICA}

BALLESTEROS, Aurora G. e CARRERAS, Carlos. Geografía y consumo. In: HIERNAUX, Daniel e LINDÓN, Alícia (Orgs). Tratado de Geografía Humana. México: Editorial Antrophos, 2006, p. 320-336. BAUMAN, Zygmnunt. Vida de consumo. Madri: Fondo de Cultura Económica, 2007.

BICUDO JR, Edison. C. 2006. O circuito superior marginal: produção de medicamentos e o território brasileiro. Dissertação (Mestrado em Geografia) - Faculdade de Filosofia, Letras e Ciências Humanas da Universidade de São Paulo, São Paulo.

BOEKE, J. H. 1953. Economics and Economic Policy of Dual Societies, as exemplified by Indonesia. Tjeenk Willink. Harleem-United Kingdom.

COMIN, Álvaro. Mudanças na estrutura ocupacional do mercado de trabalho em São Paulo. São Paulo: USP, 2003. Tese (Doutorado em Sociologia) - Faculdade de Filosofia, Letras e Ciências Humanas da Universidade de São Paulo, São Paulo.

DARDEL, Eric. L'homme et la Terre. Paris: Editions CTHS, 1952.

DAVID, Virna C. O território usado para a saúde no período da globalização os circuitos da economia urbana ligados aos equipamentos médicos. In Anais do XVI Encontro Nacional de Geógrafos. Porto Alegre, Brasil, 2010. 
DI NUCCI, J. Divisiones territoriales del trabajo y circuitos de la economía urbana en ciudades argentinas: las posibilidades técnicas de la producción de bebidas gaseosas en el circuito inferior. In Anais do XVI Encontro Nacional de Geógrafos. Porto Alegre, Brasil, 2010.

DUHAU, Emilio e GIGLIA, Angela. Nuevas centralidades y prácticas de consumo en la Ciudad de México: del microcomercio al hipermercado. Revista Eure, Santiago, v. XXXIII, n.98, p. 77-95, maio 2007.

GAUDIN, Thierry. L'écoute des silences, les institutions contre l'innovation?. Paris: Union Générale des Éditions, 1978.

GEERTZ, C. 1963. Peddlers and Princes. University of Chicago Press. Chicago-United States.

INSTITUTO BRASILEIRO DE GEOGRAFIA E ESTATÍSTICA. As Micro e Pequenas Empresas Comerciais e de Serviços no Brasil. Rio de Janeiro: FIBGE, 2003.

INSTITUTO BRASILEIRO DE GEOGRAFIA E ESTATÍSTICA. Pesquisa Nacional por Amostra de Domicílio (PNAD), Rio de Janeiro: FIBGE, 2007.

INSTITUTO BRASILEIRO DE GEOGRAFIA E ESTATÍSTICA. Pesquisa Nacional por Amostra de Domicílio (PNAD), Rio de Janeiro: FIBGE, 2009.

INSTITUTO BRASILEIRO DE GEOGRAFIA E ESTATÍSTICA. Censo Demográfico, Rio de Janeiro: FIBGE, 2010.

INSTITUTO BRASILEIRO DE GEOGRAFIA E ESTATÍSTICA. Pesquisa Nacional por Amostra de Domicílio (PNAD), Rio de Janeiro: FIBGE, 2011.

KUHN, T. The structure of scientific revolutions. University of Chicago Press. Chicago- United States., 1962

LAUTIER, B. L'économie informelle dans le Tiers Monde. Editions La Découverte. Paris-France, 1994.

LEWIS, A. Economic Development with Unlimited Supplies of Labor. School of Economics and Social

Studies. Manchester-United Kingdom, 1954.

40 LOPES dos SANTOS, Kauê. Uma financeirização da pobreza? O sistema financeiro e sua capilaridade no circuito inferior da economia urbana na cidade de São Paulo. Trabalho de Graduação individual. Departamento de Geografia da Faculdade de Filosofia, Letras e Ciências Humanas da Universidade de São Paulo. São Paulo, 2007.

McGEE, Terence. The Urbanization Process in the Third World: Explorations in Search of a Theory. Londres: G. Bell and Sons Ltd, 1971.

McGEE, Terence. The persistence of the proto-proletariat: occupational structures and planning of the future of third world cities. In ABU-LUGHOD, Janet e HAY, Richard (Orgs.). Third World Urbanization. New York: Methuen, 1977, p. 257-270.

MONTENEGRO, Marina Regitz. Globalização, trabalho e pobreza no Brasil metropolitano. O circuito inferior da economia urbana em São Paulo, Brasília, Fortaleza e Belém. São Paulo: USP, 2011. Tese (Doutorado em Geografia Humana) - Faculdade de Filosofia, Letras e Ciências Humanas, Universidade de São Paulo, São Paulo.

NERI, Marcelo. A Nova Classe Média. O lado brilhante da base da pirâmide. São Paulo: Editora Saraiva, 2011, 310 p.

OLIVEIRA, Edilson. Divisão do trabalho e circuitos da economia urbana em Londrina - PR. São Paulo: USP, 2009. Tese (Doutorado em Geografia Humana) - Faculdade de Filosofia, Letras e Ciências Humanas da Universidade de São Paulo, São Paulo.

POCHMANN, Marcio. Desenvolvimento, trabalho e renda no Brasil: avanços recentes no emprego e na distribuição dos rendimentos. São Paulo: Editora Fundação Perseu Abramo, 2010, 104 p.

QUIJANO, A. La Constitución del Mundo de la Marginalidad Urbana. Revista Eure. 3 (5): 89 106, 1972. ROCHA, Sonia. Pobreza e indigência no Brasil - algumas evidências empíricas com base na PNAD 2004. Nova Economia, Belo Horizonte, 16 (2), p. 265-299, maio-agosto de 2006.

ROCHA, Sonia. Série de dados e tabulações. Linhas de pobreza e de indigência. Instituto de Estudos do Trabalho e Sociedade (IETS), 2009.

SANTOS, Milton. L'espace partagé. Les deux circuits de l'économie urbaine des pays sous-développés. Paris: M.-Th. Génin, Librairies Techniques, 1975. 
SANTOS, Milton. O Espaço Dividido. Os dois circuitos da economia urbana dos países subdesenvolvidos. Rio de Janeiro: Francisco Alves, 1978.

SANTOS, Milton. A natureza do espaço: Técnica e tempo. Razão e emoção. São Paulo: Hucitec, 1996.

SASSEN, Saskia. Localizando ciudades en circuitos globales. Revista Eure, v.29, n.88 Santiago, p. 5-27, 2003.

SENNET, Richard. A cultura do novo capitalismo. São Paulo/ Rio de Janeiro: Record, 2006, 189 p. SERVIÇO BRASILEIRO DE APOIO ÀS MICRO E PEQUENAS EMPRESAS (SEBRAE). Participação das MPEs no total de Pessoas Ocupadas nas Empresas Paulistas. Brasília, 2000.

SILVA, Silvana Cristina. Circuito espacial produtivo das confecções e exploração do trabalho na metrópole de São Paulo: os dois circuitos da economia urbana nos bairros da Brás e Bom Retiro (SP). Unicamp, 2012. Tese (Doutorado em Geografia Humana) -, Universidade Estadual Campinas, Campinas.

SILVEIRA, María Laura. O espaço geográfico: da perspectiva geométrica à perspectiva existencial. Geousp, v. 19, p. 81-91, 2006.

SILVEIRA, María Laura. Metrópolis brasileñas: un análisis de los circuitos de la economía urbana. Revista Eure, Santiago, v. XXXIII, n.100, p. 149-164, dezembro, 2007.

SILVEIRA, María Laura. Finanças, Consumo e Circuitos da Economia Urbana na Cidade de São Paulo. Caderno CRH, v. 22, n. 55, p. 65-76, 2009.

SILVEIRA, María Laura. Da pobreza estrutural à resistência: pensando os circuitos da economia urbana. Texto apresentado no XVI Encontro Nacional de Geógrafos (ENG), Porto Alegre, 2010.

SILVEIRA, María Laura. Crises e paradoxos da cidade contemporânea: os circuitos da economia urbana. In: PEREIRA, Elson Manoel e DIAS, Leila Christina (Orgs.). As cidades e a urbanização no Brasil: passado, presente e futuro. Florianópolis: Insular, 2011, p. 62-82.

SIMONDON, Gilbert. Du mode d'éxistence des objets techniques. Paris : Aubier, $1^{\text {a }}$ ed. 1958, 1989.

SLATER, David. Capitalismo y Desarrollo Regional. Publicación del CEDLA. Amsterdan-Netherlands, 1982.

TOPALOV, Christian. La urbanización capitalista. Algunos elementos para su análisis. Mexico D.F.: Editorial Edicol, 1979, 186 p.

TORRES, Haroldo da G.; BICHIR, R. M. e CARPIM, T. P. Uma pobreza diferente?. Novos Estudos Cebrap, São Paulo, n. 74, p. 17-22, 2006.

VELTZ, Pierre. Mundialización, ciudades y territorios. Barcelona: Editora Ariel, 1999, 254 p.

\section{Sites consultados:}

Agência Nacional de Telecomunicações (ANATEL) (www.anatel.gov.br). Acesso em 02 de maio de 2013. Associação Brasileira das Empresas de Cartões de Crédito e Serviços (ABECS) (www.abecs.org.br). Acesso em 30 de janeiro de 2013.

Banco Central do Brasil (www.bcb.gov.br). Acesso em 02 de maio de 2013.

Departamento Intersindical de Estatísticas e Estudos Sócioeconômicos (DIEESE) (www.dieese.org.br). Acesso em 02 de maio de 2013.

Federação do Comércio de Bens, Serviços e Turismo do Estado de São Paulo (FecomercioSP) (www.fecomercio.com.br) 2011

Ministério do Desenvolvimento Social e Combate à Fome (MDS) (www.mds.gov.br) Acesso em 30 de janeiro de 2013.

Serviço Brasileiro de Apoio às Micro e Pequenas Empresas (SEBRAE) (www.sebrae.com.br). Acesso em 25 de novembro de 2012.

Serasa Experian (www.serasaexperian.com.br). Acesso em 20 de março de 2013.

Trabalho enviado em novembro de 2012

Trabalho aceito em janeiro de 2013 